Original Research Paper

\title{
Development of Ergonomics Guidelines for Improved Sitting Postures in the Classroom among Malaysian University Students
}

\author{
Poh Kiat Ng, Kian Siong Jee and Sin Yee Lim \\ Faculty of Engineering and Technology, Multimedia University, Malacca, Malaysia
}

\author{
Article history \\ Received: 20-04-2016 \\ Revised: $31-08-2016$ \\ Accepted: 31-08-2016 \\ Corresponding Author: \\ Poh Kiat Ng \\ Faculty of Engineering and \\ Technology, Multimedia \\ University, Malacca, Malaysia \\ Email: npohkiat@yahoo.com.sg
}

\begin{abstract}
PLIBEL stands for Plan for Identifiering av Belastnings faktorer, which is a Sweedish acronym describing a method for identification of ergonomics hazards. Using a modified PLIBEL checklist, this study aimed to identify the relationships among musculoskeletal risk factors and the classroom sitting conditions among Malaysian university students. A survey questionnaire was developed based on the modified PLIBEL checklist. A total of 142 responses were retrieved. The data was managed with SPSS version 21 and analysed using reliability analysis, normality analysis and analysis of variance (ANOVA). The results suggested that there was little correlation between the perception of the table and chair arrangements and stress factors by general repetitive movements, repetitive upper extremity movements and space/support of the workplace. Since static sitting postures were typical, students faced risks of developing common musculoskeletal disorders, especially on the lower back and upper back. A list of guidelines was recommended based on the findings to prevent potential musculoskeletal disorder symptoms.
\end{abstract}

Keywords: PLIBEL, Musculoskeletal Disorders, Ergonomics, Guidelines, Sitting Posture, ANOVA

\section{Introduction}

The advancement of technology has greatly affected and also improved man's quality of life significantly. Nowadays, young adults often spend half a day scrolling through their smart phones surfing the internet. Nevertheless, little attention is given to their health especially in their postures while enjoying the technology.

Lindsey (2012) also stated that habitual and prolonged trunk and head flexed postures are frequent in societies whose members tend to devote numerous hours daily in flexion-biased activities. One of the very common flexion-biased activities for people at all ages nowadays is sitting in front of the computer. These unhealthy norms practised by our population can cause postural dysfunction if neglected.

In general, there is no direct solution to musculoskeletal stress problems. Many factors contribute to the problem, such as postural, manual handling methods, environmental factors and so on. Since there has been a plethora of studies done on the manufacturing industry, construction industry and manual handling work, it would be of interest for this study to identify the relationships between musculoskeletal risk factors and the classroom sitting conditions among students in an educational institution. For this study, the PLIBEL method was referenced, modified and used to identify and categorise these stress factors. A survey questionnaire was developed based on the modified PLIBEL checklist in order to determine the relationships between musculoskeletal risk factors and the classroom sitting conditions among Malaysian university students.

\section{MSD Risk Factors in Relation with Potential Injurious Effects and Possible Solutions}

Musculoskeletal Disorders (MSD) can be described as a wide range of inflammatory and degenerative disorders and diseases ensuing with pain and functional impairment in the muscles, joints, ligaments, bones and tendons (Buckle and Devereux, 2002). According to the U.S. Department of Labour, musculoskeletal disorders can be caused by unnatural postures, repetition of work, prolonged static loads, improper aid and forceful exertions (Labour, 2000).

The Occupational Safety and Health Administration (OSHA) suggested that there is a relationship between MSD and workplace risk factors, which can be 
evidenced by more than 500 epidemiological studies and 1000 scientific and review articles on Work-Related Musculoskeletal Disorders (WRMSD) and workplace stress factors (Labour, 1999). The study also concluded that appropriate ergonomics programmes and ergonomic interventions can help to reduce work-related injuries and enhance workers' performance.

In another study, it was proposed that gator bar workers in a steelyard perceived $80 \%$ of MSD on their elbow, forearms and hands while 50\% risk was developed on the neck, shoulder upper back and lower back (Hudock and Wurzelbacher, 2001). In contrast to gator bar workers, shear press operators were exposed to about $40 \%$ of MSD on the neck, shoulder, upper and lower back (Hudock and Wurzelbacher, 2001). This was due to awkward postures such as extreme lumbar flexion and manual material handling of excessive loads.

Excessive handling of loads and lumbar flexion can cause Lower Back Pain (LBP), upper backache and stiff shoulders, particularly when the awkward postures were sustained for a long time. Regarding prolonged sitting, Cardon et al. (2004) stated that maintaining the same sitting posture for more than $30 \mathrm{~min}$ is considered to be prolonged sitting and that the subjects are exposed to MSD risk factors related to the lower spine. Rajaratnam and Janwantanakul (2015) mentioned that a long duration of poor postures while sitting most likely causes musculoskeletal disorders in the neck, upper back, lower back and the hips.

Another researcher also cited static siting and awkward sitting as the common causes of MSD (Gandavadi, 2008). Prolonged static sitting can decrease the blood supply to the muscles, resulting in muscle ischemia. Awkward sitting postures may also increase intradiscal pressure, thereby increasing stress on the thorax, cervical vertebra and shoulder girdle (Gandavadi, 2008).

In relation to findings from (Gandavadi, 2008; Grant, 2002) concurs that awkward neck postures and the improper twisting of the trunk are risk factors in developing musculoskeletal diseases. A person with a sustained habitual awkward neck posture may experience strain in the neck, which can lead to a chronic neck ache problem if not properly addressed.

Besides that, it was also reported that the prevalence of MSD in the upper-body postures is more rampant rather than leg postures (NIOSH, 1997). In association to this, the idea on the involvement of the knee and hips flexion at about $90^{\circ}$ each was proposed when there was a need to be seated on an average height seat (Pheasant, 1991). In regard to perceived discomfort based on the lower limb postures (typically the leg postures), it was found that a knee-flexed angle of $90^{\circ}$ or less exhibits a higher pain rating in comparison with that of $150^{\circ}$, causing victims to suffer minor symptoms of numbness and slight pain in their knee (Chung et al., 2003).
Research also revealed that people who flexed their trunk for at least $10 \%$ of their working cycle tend to have a risk of developing back disorders 9 times higher compared to others (Punnett et al., 1991). Usually, back disorders are associated with mild trunk flexion, severe trunk flexion, lateral flexion and rotational movements such as the twisting of a trunk. Hence, suggestions such as the improvement in the working space, utilisation of aids or tools for a lifting heavy load and installation of height adjustable working tables were recommended (Hayden and Koes, 2005).

According to Szeto et al. (2002), prolonged Forward Head Posture (FHP) may be one of the MSD stress factors or potential injurious effects which concurred with findings from Cardon et al. (2004). Repetition of head movements particularly in tilting the head while doing office work-typing was found to cause pronounced effects on the strain in the neck and neck ache in a long run (Szeto et al., 2002). In conjunction with the study of Szeto et al. (2002), other researches further explained that prolonged FHP tends to increase the loading in the cervical joints and muscles thus causing fatigue in muscles and neck strain (Schuldt et al., 1986).

Based on the understanding that the spine naturally rests in its normal "S" shape, researchers proposed that chair designs should maintain this sitting posture to reduce pressure on the intervertebral discs and static loads on the spinal extensors (Oborne and Rogers, 1987). Chairs with seat pan size large enough to support at least $75 \%$ of the hip or thigh provide higher ergonomic comfort to the user (Pittsburgh, 2007). A height adjustable chair could also increase the comfort level by providing ample space for the hip room when the subject sits back against his lumbar support in such a way that there will be no compression on the hips and stress in the knees (Pittsburgh, 2007).

\section{Identification of MSD Risk Factors using PLIBEL Method}

PLIBEL was established by Kristina Kemmlert in her research paper "A Method Assigned for the Identification of Ergonomic Hazards-PLIBEL" in 1995. Based on Kemmlert's literature studies on the identification of MSD, the PLIBEL checklist comprised of a series of risk factor questions, intending to investigate how musculoskeletal risk factors bring negative impacts to different body parts and cause injurious effects to the body parts.

Kemmlert (1995) also suggested the use of the PLIBEL checklist to be based on an individual or group evaluation in the particular workplace. Her study provided a foundation for professionals and researchers to form ergonomic guidelines and provide ergonomic recommendations to reduce the prevalence of MSD in society and contribute to the work site education and future research. Consequently, PLIBEL was used by many 
other researchers in investigating MSD among various specific industries, whereby one of which involved a ship construction industry (Szeto et al., 2002).

Throughout the years, it appears that PLIBEL studies have been qualitatively interpreted. It is therefore of interest to develop ergonomic guidelines based on the PLIBEL study in a quantitatively interpretable way.

\section{Materials and Methods}

A standard lecture classroom was chosen as a case study for this research because the classroom is equipped with the most common table and chair setting as shown in Fig. 1. Observations were carried out and the PLIBEL checklist was filled up. Then, a pilot study consisting of a survey questionnaire was carried out for a randomised number of 32 students from a Malaysian university. The results were analysed using factor analyses via SPSS version 21. The survey questionnaire was then restructured to develop the finalised survey questionnaire. The questionnaires were sent out to a total of 150 students from a Malaysian university based on a randomised sampling method.

Respondents were required to answer all the items of the questionnaire in all four sections, namely the perception of table and chair condition or arrangement, stress factors by general repetitive movements, stress factors by repetitive upper extremity movements and stress factors by space and support. The scale used in this questionnaire included a 5-point Likert scale where 1 indicates strongly disagree, 2 indicates disagree, 3 indicates neutral, 4 indicates agree and 5 indicates strongly agree.

After the data collection, the data was analysed using reliability analysis, normality analysis and the analysis of variance (ANOVA) via SPSS version 21. The analysis of variance or ANOVA is an appropriate statistical procedure for testing the equality of several means and to see if there are any differences between groups of variables (Montgomery, 2012). The ANOVA tells us whether the model, overall, results in a significantly good degree of prediction of the outcome variable (Field, 2009).

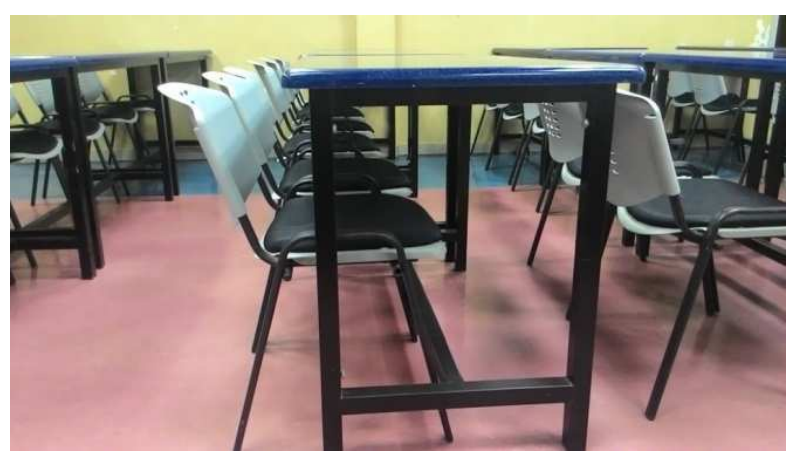

Fig. 1. Standard classroom used for the observations

\section{Results}

A total of 150 students were involved in this case study, though only 142 valid responses were retrieved for the analyses. The reliability analysis reported that the internal consistency of the results was robust and reliable for further analyses as all the Cronbach's Alpha values were within an acceptable and satisfactory range (alpha value of 0.6 and above). The Shapiro-Wilk and Kolmogorov-Smirnov normality tests also proved that the data was normal and reliable.

For the ANOVA analysis, four variables were being emphasised on. The following denotations for the relationship variables were used for the discussion:

$\mathrm{X}=$ Perception of table and chair condition or

$\mathrm{Y}_{1}=$ Stress factors caused by general repetitive movements

$\mathrm{Y}_{2}=$ Stress factors caused by repetitive upper extremity movements

$\mathrm{Y}_{3}=$ Stress factors caused by space and support of the selected workplace

Table 1 shows the types of relationships formed for the ANOVA analysis. These relationships will be analysed against the $\mathrm{X}$ variable (perception of table and chair condition or arrangement).

Based on the ANOVA analyses, the $p$-values were all found to be less than 0.05 (refer to Table 2), which confirm the significance of all the relationships in Table 1 (type 1 to type 3 ). Type 1 and type 3 relationships have weak correlations whereas the correlation for the type 2 relationship appears to be moderate. Among the 3 types of relationships, the $\mathrm{R}^{2}$ value of the relationship for type 2 (which represents the variance in the dependent variable) is the highest, which is about $14 \%$ followed by the relationships for type 1 and type 3 .

Based on the results, $14.2 \%$ of the variance in stress factors caused by repetitive upper extremity movements can be explained by table and chair condition or arrangements. Similarly, $10.2 \%$ of the variance in stress factors caused by general repetitive movements can be explained by table and chair condition or arrangements, while $9.9 \%$ of the stress factors caused by space and support of the workplace can be explained by table and chair condition or arrangements.

There was a weak but significant correlation between stress factors caused by general repetitive movements and the perception of table and chair condition or arrangements $(\mathrm{R}=0.319, \mathrm{p}<0.05)$. On the other hand, a moderate correlation is observed between stress factors caused by repetitive upper extremity movements and the perception of table and chair condition and arrangements $(\mathrm{R}=0.377, \mathrm{p}<0.05)$. Finally, the stress factors caused by space and support appear to be weakly correlated with the perception of table and chair arrangements $(\mathrm{R}=$ $0.315, \mathrm{p}<0.05)$. 
Table 1. Types of relationships formed for ANOVA analysis

\begin{tabular}{llr}
\hline Type & Types of relationship & Denotation \\
\hline 1 & $\begin{array}{l}\text { The effects of table and chair condition or arrangements on stress factors caused } \\
\text { by general repetitive movements } \\
\text { The effects of table and chair condition or arrangements on stress factors caused } \\
\text { by repetitive upper extremity movements } \\
\text { The effects of table and chair condition or arrangements on stress factors caused } \\
\text { by space and support of the workplace }\end{array}$ & $\mathrm{Y}_{1}$ versus \\
3 & $\mathrm{Y}_{2}$ versus X \\
& & $\mathrm{Y}_{3}$ versus X \\
\hline
\end{tabular}

Table 2. Variance, correlation and significance of relationship for the case study

\begin{tabular}{lllll} 
Type & Type of relationship & $\mathrm{R}^{2}(\%)$ & Significance of relationship & Correlations $(\mathrm{R})$ \\
\hline 1 & $\mathrm{Y}_{1}$ versus X & 10.2 & Significant $(\mathrm{p}<0.05)$ & 0.319 \\
2 & $\mathrm{Y}_{2}$ versus X & 14.2 & Significant $(\mathrm{p}<0.05)$ & 0.377 \\
3 & $\mathrm{Y}_{3}$ versus X & 9.9 & Significant $(\mathrm{p}<0.05)$ & 0.315 \\
\hline
\end{tabular}

\section{Discussion}

Maintaining an upright sitting posture without using a backrest further increases the load on the lumbar spine and consequently increases the intradiscal pressure (Cardon et al., 2004). In particular, students sitting with an upright pose for more than an hour appear to be users that most likely suffer from Lower Back Pain (LBP) due to compression of the tissue in the lumbar spine (Rajaratnam and Janwantanakul, 2015).

When the subject sits too far away from the whiteboard, postures such as hunchback, neck flexion and Forward Head Posture (FHP) are common in order to obtain the best vision. However, researchers found that prolonged FHP might increase the loading in the cervical joints and muscles (Schuldt et al., 1986). Hence, this position, which was observed in the observation and survey, can be a detrimental posture for the students to assume in a long run.

General repetitive movements such as fatigued leg work movements are less reported by the subjects since the subjects were exposed to a static sitting posture most of the time. Hence, the correlation between the effect of table and chair arrangements and the stress factors caused by general repetitive movements is found to be weak.

Other than that, the space for students to place their bags was restricted. Bags were either placed at the back of the seat or on the lap. These compromising solutions caused strain to the subject as placing the bag at the back of the seat tends to create an uneven lower back support while placing them on the lap causes stress on the hip and thigh, thus causing discomfort to the subjects.

It was possible that these issues were not taken into consideration seriously as these harmful postures were maintained only for a maximum of two hours per class session. Therefore, ergonomic guidelines were established to reduce the possibility of developing symptoms of musculoskeletal stress factors that cause injurious effects to students (Table 3).

In studies, subjects were advised to avoid repetitive movements with high dexterity (Wang and Lin, 2011).
Moreover, the range of motions should be reduced. Educational institutions could organise seminars or campaigns to raise the awareness of ergonomic hazards to prevent the development of musculoskeletal symptoms among students.

The potential prevalence of MSD among students may be addressed if the chairs were redesigned to provide full support on the lumbar (Pittsburgh, 2007). The current chair design in the lecture classroom of this study has only a short lumbar support and this may cause back strain when the students practise prolonged awkward sitting postures.

The presence of musculoskeletal risk factors caused by repetitive upper extremity movements can be reduced by assuming a neutral sitting posture in order to reduce intradiscal pressure, stress on the neck, shoulders and trunk and thus increasing the range of motion for the ease of work (Gandavadi, 2008). Flexion of the neck should be avoided so that the cervical extensor muscle does not become fatigued due to repetitive flexion (Szeto et al., 2002; Limerick, 2000). Loads should be handled with ergonomic postures by avoiding overexertion and twisted of trunk motions. Hayden and Koes (2005) argued that a person subjected to an awkward lifting posture while sitting tends to injure the trunk when rotational and twisted trunk motions are practised.

Despite of the weak correlation between the stress factors by space and support and the perceptions of the table and chair arrangements, the relationship is still significant. A chair with an armrest would provide a higher comfort level in such a way where one can sit with an upright shoulder-relaxed posture and place the arms on the armrest (Rajaratnam and Janwantanakul, 2015).

In addition, one should sit with both feet kept flat on the ground at all times (Clinic, 2016). This helps to support the body weight at the lumbar spine. According to Chung et al. (2003), the effect of seat height on discomfort ratings was found to be insignificant. This finding some what alluded to the weak correlation between the perception of table and chair arrangements and condition and the stress factors caused by space and support. 
Table 3. Summarised table for ergonomic guidelines

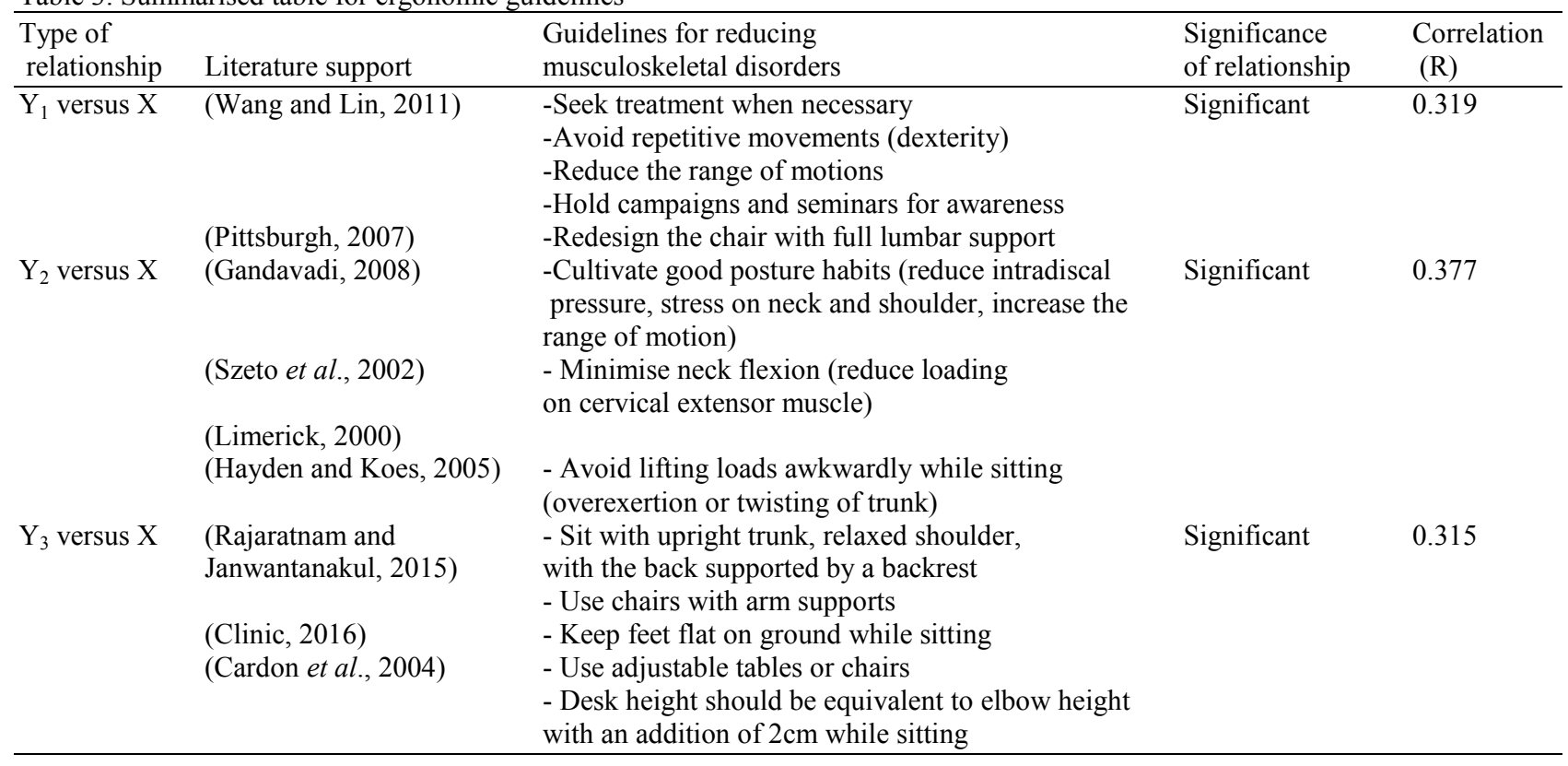

\section{Conclusion}

A modified PLIBEL checklist was formed to identify the musculoskeletal stress factors and relations among Malaysian university students. The injurious effects related to the risk factors were also determined. Even though the prevalence of MSD among the students were weakly correlated with the perception of students on table and chair condition and arrangements $\left(R_{1}=0.319\right.$, $\left.\mathrm{R}_{2}=0.377, \mathrm{R}_{3}=0.315\right)$, the relationships were significant $(\mathrm{p}<0.05)$.

A total of $14.2 \%$ of the variance in stress factors caused by repetitive upper extremity movements can be explained by table and chair condition or arrangements. Similarly, $10.2 \%$ of the variance in stress factors caused by general repetitive movements can be explained by table and chair condition or arrangements, whereas $9.9 \%$ of the stress factors caused by space and support of the workplace can be explained by table and chair condition or arrangements.

Hence, ergonomic guidelines were established based on the findings and literature to potentially prevent MSD in future. Hence, the objectives of this project were successfully achieved. These guidelines can be referenced and used not only for preliminary postural guidance to students and furniture designers but also for future studies in the area of physical ergonomics.

For future research, further observations can be carried out in order to increase the accuracy of the data and analyses. The study recommends these observations to be conducted for at least 10 lecture sessions using the modified PLIBEL checklist. Besides that, interviews can also be conducted to extend the study so as to improve and enrich the analyses of the data and findings.

\section{Acknowledgement}

The authors would like to acknowledge the Faculty of Engineering and Technology as well as the Research Management Centre of Multimedia University for the tremendous support given in conducting this research. The data presented, statements made and views expressed are solely the responsibility of the authors.

\section{Funding Information}

This research was supported by the Faculty of Engineering and Technology and Research Management Centre of Multimedia University Malaysia.

\section{Author's Contributions}

Poh Kiat Ng: Dr. Ng was in charge of the planning, execution and data collection of this study. He conducted some of the literature research as well. He also constructed the survey protocol and analysed the data collected for the study. He provided the major inputs for the discussions and conclusions.

Kian Siong Jee: Mr. Jee was involved in conducting some of the literature research of the study. He was also involved in the survey data collection and administration. He conducted and advised part of the analyses of the data as well.

Sin Yee Lim: Ms. Lim was involved in most of the literature research of the study. She was also involved in the data interpretation and conclusion of the study. The ergonomics guidelines were compiled and summarised by her as well. 


\section{Ethics}

This article is original and contains unpublished material. The corresponding author confirms that all the other authors have read and approved the manuscript. Hence, no ethical issues are involved.

\section{References}

Buckle, P. and J. Devereux, 2002. The nature of workrelated neck and upper limb musculoskeletal disorders. Applied Ergonom., 33: 207-217. DOI: $10.1016 / \mathrm{S} 0003-6870(02) 00014-5$

Cardon, G., D.D. Clercq and D. Breithecker, 2004. Sitting habits in elementary schoolchildren: A traditional versus a "moving school". Patient Educ. Counsel., 54: 133-142. DOI: 10.1016/S0738-3991(03)00215-5

Chung, M.K., I. Lee and D. Kee, 2003. Assessment of postural load for lower limb postures based on perceived discomfort. Int. J. Industrial Ergonom., 31: 17-32. DOI: 10.1016/S0169-8141(02)00115-4

Clinic, C., 2016. Posture for a healthy back. Cleveland Clinic.

Field, A., 2009. Discovering Statistics Using Spss. 3rd Edn., SAGE Publications, Los Angeles, ISBN-10: 1847879071, pp: 821.

Gandavadi, A., 2008. Working postures in dental practitioners and dental students: Relationships between posture seating and muscle activity. eTheses Repository, 204: 109-498.

Grant, R., 2002. Physical Therapy of the Cervical and Thoracic Spine. 3rd Edn., Churchill Livingstone.

Hayden, J.A. and B.W. Koes, 2005. Meta-analysis: Exercise therapy for nonspecific low back pain. Ann. Intern. Med., 142: 75-765. PMID: 15867409

Hudock, S.D. and S.J. Wurzelbacher, 2001. Preintervention quantitative risk factor analysis for ship construction processes.

Kemmlert, K., 1995. A method assigned for the identification of ergonomic hazards-PLIBEL. Applied Ergonom., 26: 199-211. DOI: 10.1016/0003-6870(95)00022-5

Labour, U.D., 1999. Ergonomics Programme. Occupational Health and Safety Administration, Washington, USA.

Labour, U.S.D., 2000. Human factors engineering handbook: The study of work. Occupational Safety and Health Administration, Washington, USA.

Limerick, R.B., 2000. Gaze angle, heterophoria and neck biomechanics: Implications for the height of visual displays. Proceedings of the 36th Annual Conference of the Ergonomics Society of Australia, (ESA’ 00), Adelaide, Australia.
Lindsey, C., 2012. Geriatric Physical Therapy. 3rd Edn., Elsevier, Bristol, UK.

Montgomery, D.C., 2012. Design and Analysis of Experiments. 8th Edn., John Wiley and Sons, New York, ISBN-10: 1118097939, pp: 730.

NIOSH, 1997. Musculoskeletal disorders and workplace factors-a critical review of epidemiologic evidence for work-related musculoskeletal disorders of the neck, upper extremity and low back. The National Institute for Occupational Safety and Health (NIOSH).

Oborne, D.J. and Y. Rogers, 1987. Pictorial communication of abstract verbs in relation to human-computer interaction. Brit. Psychol. Society, 78: 99-112. DOI: $10.1111 / \mathrm{j} .2044-8295.1987 . t b 02229 . x$

Pheasant, S.T., 1991. Ergonomics Work and Health. 1st Edn., Aspen Publishers, Houndmills, ISBN-10: 0871893207, pp: 358.

Pittsburgh, U.O., 2007. How to Choose an Ergonomic Chair. University of Pittsburgh.

Punnett, L., L.J. Fine and W.M. Keyserling, 1991. Back disorders and nonneutral trunk postures of automobile assembly workers. Scandinavian J. Work Environ. Health, 17: 337-346. PMID: 1835131

Rajaratnam, B.S. and P. Janwantanakul, 2015. Perceived body discomfort and trunk muscle activity in three prolonged sitting postures. J. Phys. Ther. Sci., 27: 2183-2187. DOI: 10.1589/jpts.27.2183

Schuldt, K., J. Ekholm and U.P. Arborelius, 1986. Effects of changes in sitting work posture on static neck and shoulder muscle activity. J. Ergonom., 29: 1525-1537. DOI: 10.1080/00140138608967266

Szeto, G.P.Y., L. Straker and S. Raine, 2002. A field comparison of neck and shoulder postures in symptomatic and asymptomatic office workers. Applied Ergonom., 33: 75-84. DOI: $10.1016 / \mathrm{S} 0003-6870(01) 00043-6$

Wang, M.L. and H.F. Lin, 2011. The analysis of musculoskeletal disorder in workers in the food and baking industry. Proceedings of the IEEE 18th International Conference on Industrial Engineering and Engineering Management, Sept. 3-5, IEEE Xplore Press, Changchun, China. DOI: 10.1109/ICIEEM.2011.6035395 